\title{
A Lagrangean decomposition approach for a novel two-echelon node-based location-routing problem in an offshore oil and gas supply chain
}

\author{
Mohsen Amiri a , Saman Hassanzadeh Amin ${ }^{\text {a, }}$, Reza Tavakkoli-Moghaddam ${ }^{\text {b,c }}$ \\ ${ }^{a}$ Department of Mechanical and Industrial Engineering, Ryerson University, ON, Canada \\ ${ }^{b}$ School of Industrial Engineering, College of Engineering, University of Tehran, Tehran, Iran \\ ${ }^{c}$ Arts et Métiers ParisTech, LCFC, Metz, France
}

\footnotetext{
* Corresponding author.

E-mail address: saman.amin@ryerson.ca (Saman Hassanzadeh Amin).
} 


\title{
A Lagrangean decomposition approach for a novel two-echelon node-based location-routing problem in an offshore oil and gas supply chain
}

\begin{abstract}
In this paper, a new node-based mixed-integer non-linear programming (MINLP) model in an offshore oil and gas industry is proposed. The model, which is a supply vessel planning (SVP) one, is developed to a two-echelon fleet composition mix periodic location-routing problem with time windows (2E-FCMPLRPTW). In the first echelon, the number and type of vehicles, routes, schedules and the best allocation of suppliers are determined. In the second echelon, the number and type of supply vessels, related voyages and schedules are calculated. A Lagrangean decomposition method, which is a particular case of Lagrangean relaxation, is presented to solve the problem.
\end{abstract}

Keywords: Offshore oil and gas industry; Supply vessel planning; Location-routing; Lagrangean decomposition; Fleet composition.

\section{Introduction}

Supply vessel planning (SVP) is one of the most important parts in upstream offshore logistics in order to make sure that all needed installations are sent at the right time (Kisialiou et al., 2018a). A basic SVP problem refers to a system that includes one onshore base, some special supply vessels, and final customers in upstream (Kisialiou et al., 2018b). Upstream is one of the critical parts of an offshore oil and gas supply chain. In order to produce oil and gas in the sea continuously, materials, equipment, and other consumables should be sent to offshore units. Supply vessels, which are very costly, are the only vessels to send cargoes to offshore units and return backloads to onshore bases. A basic SVP model is aimed to determine the number of supply vessels and related voyages to satisfy the demands of final customers. In this model, the total cost of the system that contains routing and supply vessels costs is minimized (Halvorsen-Weare et al., 2012). Figure 1 shows the basic SVP model. 

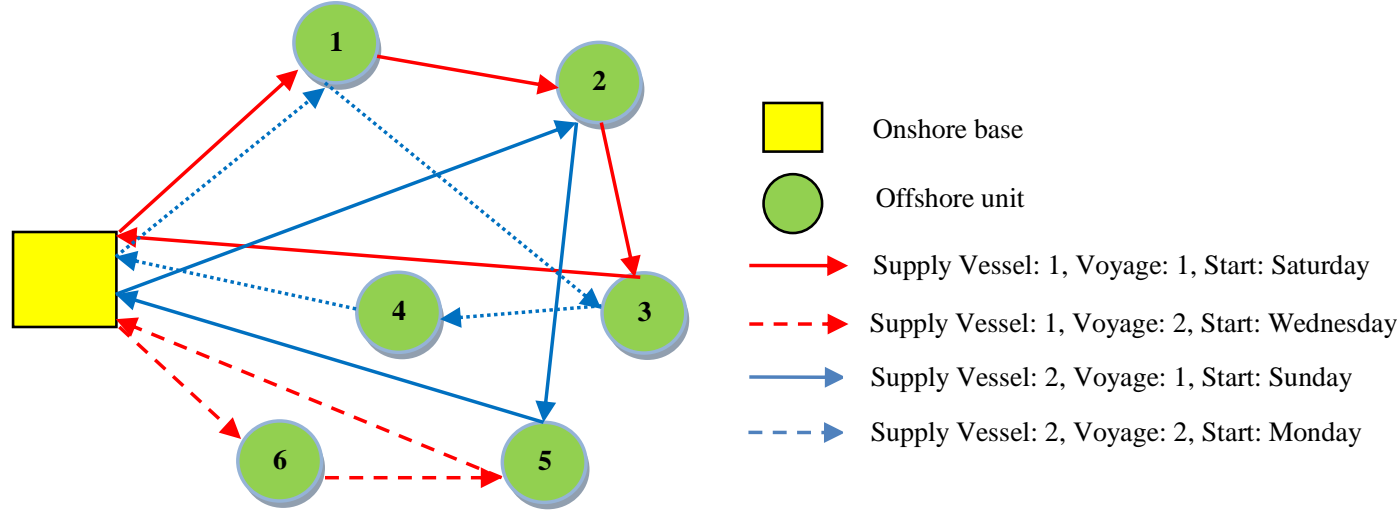

Figure 1. Basic SVP model

\subsection{Review of the literature}

For the first time, the basic SVP model was presented by Fagerholt and Lindstad (2000) during a project, which was requested by Statoil Company in the Norwegian Sea. The aim of the study was to analyze the effects of having some or all offshore units closed during night on the total cost. The results showed that the company could save about seven million dollars during a year by implementing this method. In the other study in the Norwegian oil and gas industry by Aas et al. (2007), the effects of limitations in offshore unit's capacity were investigated. A mixed-integer linear programming (MILP) model was presented and tested for different real-life cases. Gribkovskaia et al. (2008) presented a new SVP model by considering pickups, deliveries, and backloads. The purpose of the model is to minimize the total cost of chartering supply vessels and sailing distances, while the needed cargoes of offshore units are supplied. In their model, supply vessels must start and finish their voyages from the same onshore base. A tabu search (TS) algorithm was introduced for large cases.

Iachan (2009) presented a new model of a fleet sizing mix vehicle routing problem (FSMVRP) for special supply vessels. Simulation and operations research were used in this study. The model was implemented in Petrobras, which is the biggest Brazilian oil company. A genetic algorithm (GA) was used to solve it. Aas et al. (2009) mentioned the role of supply vessels as the highest cost element in upstream logistics. Loading and unloading capabilities and capacities of supply vessels were mentioned as the most important features in their model. Shyshou et al. (2010) presented a fleet sizing model for anchor handling operations, and used a simulation model to determine the optimal fleets, which should be chartered for a long time to manage future operations. Halvorsen-Weare and Fagerholt (2011) presented a robust model for a SVP problem for the first time. Applying different approaches and considering weather conditions are unique features in their model. Halvorsen-Weare et al. (2012) used a two-stage 
voyage-based approach to find the optimal fleet composition of supply vessels, related weekly voyages, and schedules in the Norwegian Sea. They illustrated the application of the model by studying a case. Furthermore, a what-if analysis to find the possibility of using one less supply vessel was utilized.

In order to solve large instances of a periodic SVP problem, a heuristic adaptive large neighborhood search (ALNS) was developed by Shyshou et al., (2012). Norlund et al. (2015) applied a simulation-optimization method by considering the speed of supply vessels as a new parameter. Christiansen et al. (2017) considered a real-case of the FSMVRP for fuel supply vessels in a port. They used arc-flow and path-flow models to formulate the problem. The results of the path-flow model were better than the results of the arc-flow model. Cuesta et al. (2017) presented a new vehicle routing problem (VRP) with selective pickups and deliveries (VRPSPD) in an offshore oil and gas industry. Furthermore, a multi-VRP with pickups and deliveries (MVRPPD) was introduced. Dulebenets and Ozguven (2017) presented a new MINL model for a vessel scheduling problem in a liner shipping route. The aim of their model was to decrease the total cost of routing. The results showed that the model can be an effective planning tool for this kind of problem. A new strategy to reduce the total cost and delivery time in a maritime bilateral trade problem was presented by Jeong et al., (2018). The results of some meta-heuristic algorithms were compared in this study.

Offshore oil and gas companies deal with two significant problems. The first problem is the optimal fleet composition and designing routes, and the second one is the location of the onshore base(s). Some studies have shown that location and routing decisions are not independent. If they are considered separately, they may lead to sub-optimal planning results (Koç et al., 2016). The basic location-routing problems (LRPs) include arbitrary types of facilities (e.g., plants, depots, warehouses, hubs, and cross-docks) with opening costs and a set of customers with recognized demands. The goal is to minimize the total cost of deciding the number and locations of the facilities over a set of feasible locations, the number of vehicles to distribute the products, and related routes to fulfil the needed demand of final customers (Drexl and Schneider, 2015). LRPs are considered as NP-hard combinatorial optimization problems. Some algorithms have been presented to solve LRPs, such as greedy randomized adaptive search procedure (GRASP) by Prins et al., (2006), GA by Derbel et al., (2012), simulated annealing (SA) by Vincent et al., (2010), ANLS by Hemmelmayr et al., (2012), variable neighborhood search (VNS) by Jarboui et al., (2013), and adaptive variable neighborhood search (AVNS) by Hof et al., (2017). In addition, some exact methods for 
capacitated and uncapacitated LRPs have been developed (e.g., Albareda-Sambola et al., 2005 and Belenguer et al., 2011).

Two-echelon LRPs (2E-LRPs) are new and challenging optimization problems in LRPs, which consider location and routing decisions in two-echelon supply chains (Pichka et al., 2018). In this type of LRPs, the routes are designed to send goods to depots. Figure 2 shows an example, in which these routes make the first echelon. In addition, the routes from the selected depots to the final customers make the second echelon (Prodhon and Prins, 2014).

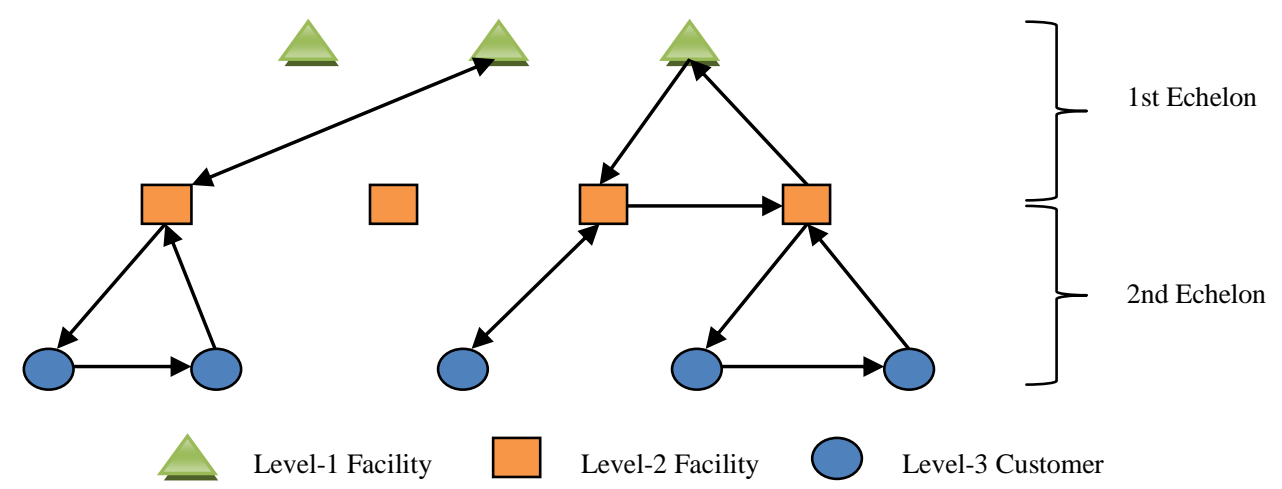

Figure 2. Two-echelon location-routing problem (2E-LRP)

The first study about 2E-LRPs was published by Jacobsen and Madsen (1980), who developed a 2E-LRP for a newspaper distribution problem. Lin and Lei (2009) presented a new 2E-LRP model, which includes two kinds of customers and some depots. The goal of this model was to locate the distribution centers, and design the routes in both echelons. A GA was introduced to solve the model using a cluster-based routing heuristic algorithm. The computational study showed that the proposed method for small cases obtains the results of the exact methods. In the other study, a 2E-LRP with a single center depot and some potential depots was presented by Nguyen et al., (2012). They considered some depots with different opening costs and limited capacities.

Schwengerer et al. (2012) and Contardo et al. (2012) presented new models for 2E-LRPs. Rahmani et al. (2015) presented a LRP-MPPD-2E model by adding three new concepts (i.e., multi-product, pickup and delivery, and using processing center as an intermediate facility) to the basic LRP-2E. In addition, they presented two local search methods to solve the problem. Zhao et al. (2018) presented a new 2E-LRP in a parcel delivery industry. In addition, they developed a new heuristic algorithm to solve the model. Pickka et al. (2018) introduced a twoechelon open LRP (2E-OLRP). In this model, the vehicles do not return to the depots. The authors presented a hybrid heuristic algorithm to solve this problem. 
According to the literature review, 2E-LRPs have been used in some real-life cases. However, no paper has considered a 2E-LRP for SVP problems. Therefore, appropriate models should be developed to fill this research gap. Our paper focuses on the 2E-LRP for SVP problems.

\subsection{Research contributions}

In this paper, for the first time in an oil and gas upstream supply chain, a novel twoechelon fleet composition mix periodic location-routing problem by considering time windows (2E-FCMPLRPTW) is presented. The problem is a node-based one. In this paper, a unique mathematical model is proposed to solve the problem. Considering suppliers and defining a road-based periodic routing problem in the first echelon to send cargoes to potential onshore bases are unique features of this model. The presented model is comprehensive and includes number and type of road vehicles considering time windows for potential onshore-bases. Locating central warehouses by considering some practical attributes (e.g., type and number of allowable supply vessels) is another feature of this study.

In this research, an innovative solution approach based on some new heuristic methods is developed to convert the model into a linear programming model. This model is helpful to obtain the optimal solutions in a reasonable time. A Lagrangean decomposition method, which is a certain part of the Lagrangean relaxation method is developed to find the solutions. This method is based on partitioning the original problem into several sub-problems. Finally, the proposed model and the solution approaches are applied in a real case, and the results are analyzed. The results of the case study show noticeable economic improvements.

The purpose of the proposed model is to decide the number, type, routes and voyages of heterogeneous vehicles in both echelons while the total cost is kept minimum. In addition, some factors (e.g., optimal onshore bases) in order to install central warehouse(s) and the best allocation of suppliers to send cargoes to the central warehouse(s) are determined.

The rest of this paper is organized as follows. In Section 2, the problem is described. Then, a novel mathematical model is proposed in Section 3. Section 4 is devoted to the proposed solution approach. In Section 5, the application of the model and the computational results are discussed. Finally, conclusions and future research are provided in Section 6. 


\section{Problem definition}

In this section, a 2E-FCMPLRPTW is introduced as an extension of SVP model in an offshore oil and gas industry. The basic SVP model is a mixture of a fleet composition problem and a maritime transportation problem. The new system consists of three dependent levels by considering heterogeneous road and marine vehicles as depicted in Figure 3.

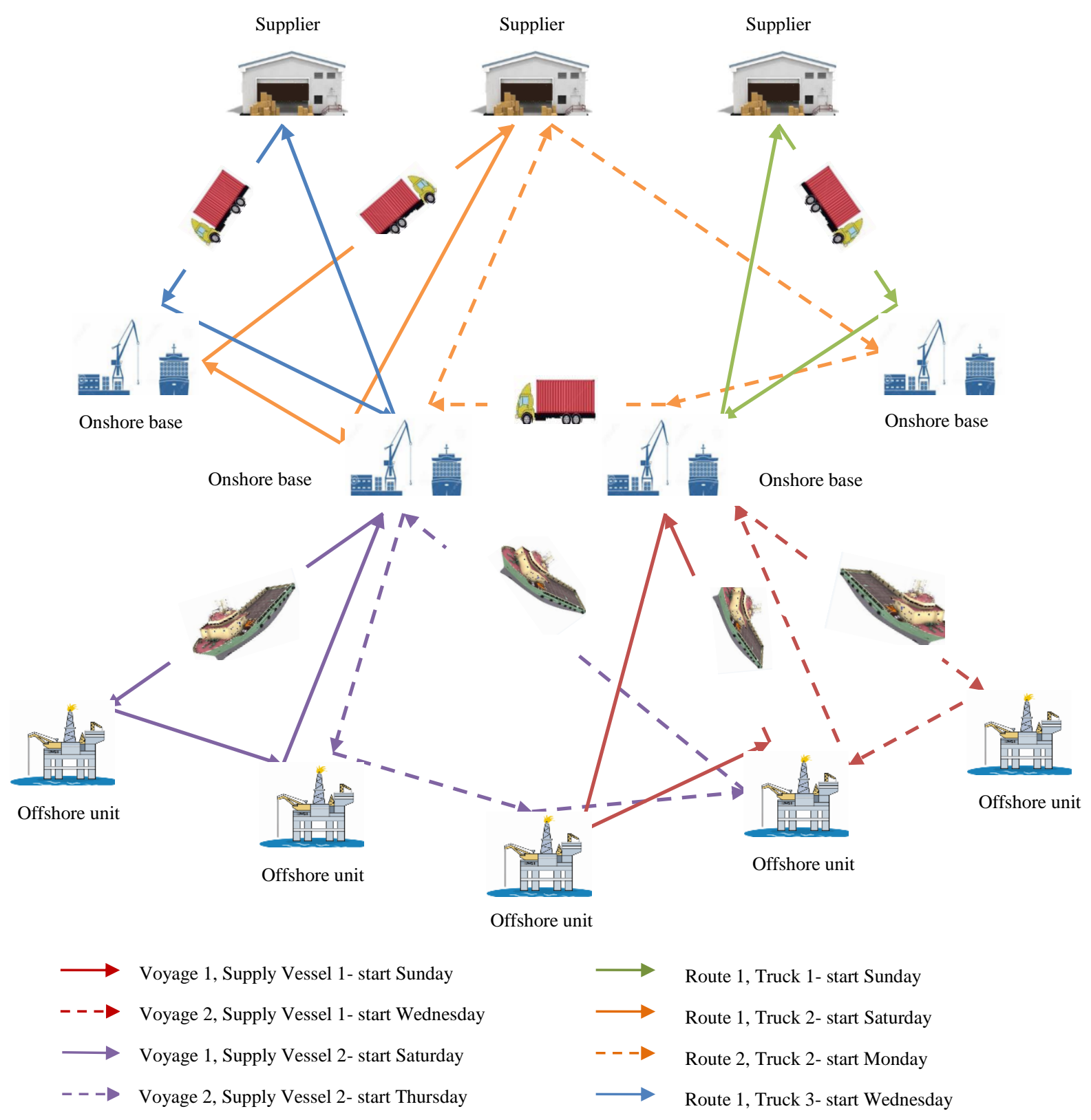

Figure 3. 2E-FCMPLRPTW model 
In an offshore oil and gas industry, most installations and operational regions are located in the sea. In order to supply final customers (i.e., offshore units), some onshore purchasing offices (i.e., suppliers) are required. In addition, different road vehicles to send cargoes from suppliers to onshore bases are available. Each road vehicle is allowed to load from a certain supplier, and to visit different onshore bases to unload the cargoes. Some potential onshore bases to berth marine vehicles are available. The customer's needs are sent from the selected onshore bases to the offshore units by supply vessels. Offshore units are the final customers of this system. They are supplied during a time horizon by different heterogeneous marine vehicles.

This system is aimed to obtain the number and type of road vehicles (trucks), related routes and their schedules, and assignment of open onshore base(s) to suppliers in the first echelon. In the second echelon, the selection of optimal onshore base(s) in order to install central warehouse(s), the number and type of marine vehicles, related weekly voyages, and their schedules are determined. The total cost of both echelons should be kept minimum, and the needs of final customers must be fulfilled (Ehmke et al., 2018).

The assumptions of the problem and the related model are as follows:

1. Each route in the first echelon starts from a supplier, serves one or more onshore bases, and returns to the same supplier (i.e., VRP). In the second echelon, each voyage starts from an onshore base, serves one or more customers, and returns to the same onshore base in the second level (i.e., VRP).

2. The needs of offshore units are considered as a single-commodity, and the demands of offshore units are known at the beginning of the period.

3. All levels of the system are capacitated. The capacities of offshore units to receive cargoes in different days are various. Suppliers and onshore bases have different capacities. In addition, potential onshore bases have different opening and variable costs, and different capacities to install central warehouses (i.e., capacitated LRP).

4. There is no limitation for using different facilities and vehicles in each echelon (i.e., multiple sourcing).

5. Different kinds of vehicles with various fixed and variable costs and capacities in both echelons are considered (i.e., heterogeneous fleets).

6. In the first echelon, a time horizon by considering two days (i.e., 48 hours), and in the second echelon, a time horizon by considering seven days (i.e., 168 hours) are assumed for sending cargoes from suppliers to offshore units (periodic). Furthermore, the demands of offshore units are estimated for one week (i.e., weekly demand). 
7. The potential onshore bases and offshore units have opening hours. Loading and unloading are allowed during these hours. The potential onshore bases are open between 8:00 and 16:00 for unloading cargoes from road vehicles and for loading marine vehicles. Offshore units are open between 7:00 and 19:00 for unloading needs and loading backloads (i.e., time windows).

8. Different service times for loading and unloading of vehicles in both echelons are considered.

9. Some offshore units should be visited a number of certain times during a week by marine vehicles.

10. The type of supply vessels in potential onshore bases is important. Some onshore bases are not capable to service large-sized supply vessels.

11. Experience has shown that the deck capacity is more important than the bulk capacity for supply vessels to send cargoes to offshore units.

12. The volumes of backloads of offshore units are considered less than their demands. Therefore, there will be enough spaces to transfer them.

13. It is necessary to consider the spread of departures in order to minimize the total cost in an offshore oil and gas industry. For instance, consider an offshore unit, which needs two visits during a week, and both visits are done on Saturday and Sunday. If there is a necessary visit on Monday, an extra supply vessel must be sent to the offshore unit that increases the total cost.

14. The duration of a route is a function of the distance, the speed of road vehicles, and the service time for all potential onshore bases which should be visited on a route.

15. The duration of a voyage is a function of the sailing distance, the speed of supply vessels, and the service time for all offshore units which should be visited on a voyage.

The node-based 2E-FCMPLRPTW model is presented for the first time in this paper. Table 1 includes some information about the model. Considering suppliers with different features, limitation in the type of marine vehicles in onshore bases, installing central warehouse(s) to reduce the total cost by considering different fixed and variable costs, considering time windows for central warehouses, and using Lagrangean decomposition method to solve the problem are the most important research contributions of this paper. 
Table 1. Comparison of basic models with the present study

\begin{tabular}{|c|c|c|c|}
\hline Title & $\begin{array}{c}\text { Fagerholt and } \\
\text { Lindstad (2000) }\end{array}$ & $\begin{array}{c}\text { Halvorsen-Weare } \\
\text { et al. (2012) }\end{array}$ & $\begin{array}{c}\text { Proposed } \\
\text { model }\end{array}$ \\
\hline New mathematical model & $\nabla$ & $\nabla$ & $\nabla$ \\
\hline Marine fleet composition & $\square$ & $\nabla$ & $\nabla$ \\
\hline Marine periodic routing & $\square$ & $\square$ & $\nabla$ \\
\hline $\begin{array}{l}\text { The possibility of more than one visit for } \\
\text { customers }\end{array}$ & $\nabla$ & $\square$ & $\square$ \\
\hline Simulates delivery and pick up & $\nabla$ & $\nabla$ & $\nabla$ \\
\hline Considering time windows for offshore units & $\square$ & $\square$ & $\square$ \\
\hline Capacity of central warehouses & & $\square$ & $\square$ \\
\hline Considering variable cost for supply vessels & & $\square$ & $\nabla$ \\
\hline Spread of departures & & $\square$ & $\nabla$ \\
\hline $\begin{array}{l}\text { Node-based two-echelon location-routing } \\
\text { model }\end{array}$ & & & $\square$ \\
\hline Considering suppliers & & & $\square$ \\
\hline Locating central warehouses & & & $\nabla$ \\
\hline $\begin{array}{l}\text { Considering variable cost for cargoes in } \\
\text { central warehouses }\end{array}$ & & & $\square$ \\
\hline Road fleet composition & & & $\square$ \\
\hline Considering capacity for road vehicles & & & $\nabla$ \\
\hline Road-based periodic routing problem & & & $\square$ \\
\hline $\begin{array}{l}\text { Considering time windows for unloading in } \\
\text { central warehouses }\end{array}$ & & & $\nabla$ \\
\hline $\begin{array}{l}\text { Considering capacity for receiving cargoes } \\
\text { with offshore units }\end{array}$ & & & $\nabla$ \\
\hline $\begin{array}{l}\text { Capacity limitation for the type of vehicles in } \\
\text { onshore bases }\end{array}$ & & & $\square$ \\
\hline $\begin{array}{l}\text { Relaxation method (Lagrangean } \\
\text { decomposition) }\end{array}$ & & & $\square$ \\
\hline
\end{tabular}

\section{Proposed model}

In our study, we refer a two-echelon location routing problem when the problem involves both strategic and tactical planning decisions, and routes are present at both echelons. In our model, the available goods at different origins (suppliers) have to be delivered to the respective destinations (final customers) moving mandatory through intermediate facilities (potential onshore bases). In this section, a new mathematical model is presented. The model determines the optimal type and number of road and marine vehicles, the optimal routes and voyages and related schedules, and the optimal locations of the onshore base(s) in order to send the needs of the offshore units by minimizing the total cost.

\subsection{Mathematical model}

Tables 2 to 5 include sets, indices, parameters, and decision variables. 
Table 2. Definitions of the sets in the new model

\begin{tabular}{ll}
\hline Sets & Definition \\
\hline Node & Set of suppliers, potential onshore bases and offshore units \\
Node $1 \subseteq$ Node & Set of suppliers, potential onshore bases \\
$B \subseteq$ Node & Set of potential onshore bases to install central warehouse(s) \\
$S \subseteq$ Node & Set of suppliers \\
$K$ & Set of road vehicles \\
Node $2 \subseteq$ Node & Set of potential onshore bases and offshore units \\
$C \subseteq$ Node & Set of offshore units \\
$C_{2} \subseteq C$ & Set of offshore units that need two weekly visits \\
$C_{3} \subseteq C$ & Set of offshore units that need three weekly visits \\
$C_{4} \subseteq C$ & Set of offshore units that need four weekly visits \\
$V$ & Set of marine vehicles \\
Day & Set of days of a week \\
Tour $R$ & Set of tours in the first echelon \\
Tour $V$ & Set of tours in the second echelon \\
\hline
\end{tabular}

Table 3: Definitions of the indices in the new model

\begin{tabular}{ll}
\hline Indices & Definition \\
\hline node $1, n 1 j, n 1 i$ & Indices of suppliers and potential onshore bases \\
$j, b i, b j$ & Indices of potential onshore bases \\
\multicolumn{1}{c}{$s, s S$} & Indices of suppliers \\
$k$ & Index of road vehicles \\
$n o d e 2, n 2 j, n 2 i$ & Indices of potential onshore bases and offshore units \\
$c, c i, c j$ & Indices of offshore units \\
$v$ & Index of marine vehicles \\
day & Index of the days in a week \\
tour & Index of the tours in both echelons \\
\hline
\end{tabular}


Table 4. Definitions of the parameters in the new model

\begin{tabular}{|c|c|}
\hline Parameters & Definition \\
\hline$c f_{k}^{R}$ & Fixed cost of road vehicle $k$ \\
\hline$c v_{k}^{R}$ & Variable cost of road vehicle $k$ per kilometer \\
\hline $\operatorname{spead}_{k}^{R}$ & Average velocity of road vehicle $k$ per one hour \\
\hline$c_{j}^{b f}$ & Fixed cost of installing central warehouses in onshore base $j$ \\
\hline$c_{j}^{b v}$ & Variable cost of per unit of cargo in onshore base $j$ \\
\hline$c_{s}^{s u}$ & Purchasing cost of per unit of cargo from supplier $s$ \\
\hline $\operatorname{cap}_{k}^{R}$ & Capacity limitation of road vehicle $k$ \\
\hline $\operatorname{cap}_{j}^{b}$ & Capacity limitation of onshore base $j$ \\
\hline $\operatorname{cap}_{s}^{s u}$ & Capacity limitation of supplier $s$ \\
\hline$N p$ & Number of needed onshore bases \\
\hline $\operatorname{Dis}_{n 1 i, n 1 j}$ & Distance between suppliers and onshore bases \\
\hline stop $p_{k, \text { node } 1}^{1}$ & Stop time of road vehicle $k$ in the first echelon \\
\hline$f_{v}$ & Allowable days of using marine vehicles \\
\hline$e_{j v}$ & Allowable type of marine vehicles in onshore-base $j$ \\
\hline $\operatorname{dem}_{c}$ & Demand of offshore unit $c$ \\
\hline$s n_{c}$ & Number of needed visits for offshore unit $c$ \\
\hline$u_{d a y, c}^{C}$ & Daily capacity of offshore unit $c$ to receive needs \\
\hline$u_{\text {day }, j}^{B}$ & Daily capacity of onshore base $j$ to load marine vehicles \\
\hline$\left[w L_{c}, w R_{c}\right]$ & Time windows of offshore unit $c$ to receive needs \\
\hline$c f_{v}^{V}$ & Fixed cost of vehicle $v$ \\
\hline$c v_{v}^{V}$ & Variable cost of vehicle $v$ \\
\hline $\operatorname{spead}_{v}^{V}$ & Velocity of marine vehicle $v$ \\
\hline stop $p_{v, \text { node2 }}^{2}$ & Stop time of vehicle $v$ in the second echelon \\
\hline $\operatorname{cap}_{v}^{V}$ & Capacity of marine vehicle $v$ \\
\hline$D i s_{n 2 i, n 2 j}^{M}$ & Distance between onshore bases and offshore units \\
\hline$M$ & Very large number \\
\hline
\end{tabular}


Table 5. Definitions of the variables in the new model

\begin{tabular}{|c|c|}
\hline Variables & Definition \\
\hline$z_{k, S}^{R}$ & 1 if vehicle $k$ is assigned to supplier $s ; 0$, otherwise \\
\hline$Y_{j}$ & 1 if onshore base $j$ is selected; 0 , otherwise \\
\hline$X_{\text {tour }, k, n 1 i, n 1 j}^{1}$ & 1 if road vehicle $k$ starts a special tour; 0 , otherwise \\
\hline$Q_{s, j, t o u r, k}^{s u}$ & Quantity of sending cargoes from supplier $s$ to onshore base $j$ by vehicle $k$ \\
\hline time $e_{\text {node } 1, \text { tour }, k}$ & Visiting time a supplier or an onshore base by vehicle $k$ on a certain tour \\
\hline$U_{\text {tour }, k, j}^{1}$ & Slack variable to omit the sub tour of vehicle $k$ on a special tour \\
\hline$z_{v, j}^{V}$ & 1 if vehicle $v$ is assigned to onshore $j ; 0$, otherwise \\
\hline$X_{\text {tour }, v, n 2 i, n 2 j}^{2}$ & 1 if vehicle $v$ starts a special tour; 0 , otherwise \\
\hline$Q_{j, c . t o u r, v}^{b}$ & Quantity of sending cargoes from onshore base $j$ to offshore unit $c$ by vehicle $v$ \\
\hline time $e_{\text {node } 2, \text { tour }, v}$ & Visiting time of an onshore base or an offshore unit by vehicle $v$ on a certain tour \\
\hline$X_{\text {day, node2,tour }, v}$ & 1 if vehicle $v$ on a special day visits an onshore base or an offshore unit; 0 , otherwise \\
\hline$Q_{\text {day }, j, c, t o u r, v}$ & Quantity of sending cargoes from onshore base $j$ to offshore unit $c$ by vehicle $v$ \\
\hline$U_{\text {tour }, v, c}^{2}$ & Slack variable to omit the sub tour of vehicle $v$ on a special tour \\
\hline$\xi_{j, k, t o u r}^{1}$ & Integer slack variable to define the problem as a linear programming \\
\hline$\xi_{j, k, \text { tour }}^{2}$ & Integer slack variable to define the problem as a linear programming \\
\hline$\xi_{c, k, t o u r}^{2}$ & Integer slack variable to define the problem as a linear programming \\
\hline$X_{\text {day,node2,tour }, v}^{\prime}$ & Binary slack variable to define the problem as a linear programming \\
\hline$X_{\text {day,node2,tour }, v}^{\prime \prime}$ & Binary slack variable to define the problem as a linear programming \\
\hline$\theta_{c}$ & Binary slack variable to define the spread of departures \\
\hline
\end{tabular}

The mathematical model for the node-based 2E-FCMPLRPTW problem is as follows:

Min Cost $=Z_{1}+Z_{2}$

$$
\begin{aligned}
& \begin{array}{l}
Z_{1}=\sum_{k} \sum_{s} c f_{k}^{R} \cdot z_{k, s}^{R}+\sum_{j} c_{j}^{b f} \cdot Y_{j}+\sum_{s} \sum_{j} \sum_{\text {tour }} \sum_{k} c_{j}^{b v} \cdot Q_{s, j, t o u r, k}^{s u}+\sum_{s} \sum_{j} \sum_{\text {tour }} \sum_{k} c_{s}^{s u} \cdot Q_{s, j, t o u r, k}^{s u} \\
\quad+\sum_{\text {tour }} \sum_{k} \sum_{n 1 i} \sum_{n 1 j} c v_{k}^{R} \cdot D i s_{n 1 i, n 1 j} \cdot X_{\text {tour }, k, n 1 i, n 1 j}^{1} \\
Z_{2}=\sum_{v} \sum_{j} c f_{v}^{V} \cdot z_{v, j}^{V}+\sum_{\text {tour }} \sum_{v} \sum_{n 2 i} \sum_{n 2 j} c v_{v}^{V} \cdot D i s_{n 2 i, n 2 j}^{M} \cdot X_{\text {tour }, v, n 2 i, n 2 j}^{2}
\end{array} \\
& \text { s.t. } \\
& \sum_{s} z_{k, s}^{R}=1 ; \forall k \\
& \sum_{j} Q_{s, j, t o u r, k}^{s u} \leq c a p_{k}^{R} ; \forall s, k, \text { tour } \\
& \sum_{j} X_{\text {tour }, k, s, j}^{1} \leq z_{k, s}^{R} ; \forall s, k, \text { tour }
\end{aligned}
$$


$\sum_{j} \sum_{\text {tour }} Q_{s, j, t o u r, k}^{s u} \leq M \cdot z_{k, s}^{R} ; \forall s, k$

$Q_{s, j, t o u r, k}^{s u} \leq M . \sum_{n 1 i} X_{\text {tour }, k, n 1 i, j}^{1} ; \forall s, j, k$, tour

$\sum_{s} \sum_{\text {tour }} \sum_{k} Q_{s, j, t o u r, k}^{s u} \leq c a p_{j}^{b} . Y_{j} ; \forall j$

$\sum_{j} \sum_{\text {tour }} \sum_{k} Q_{s, j, t o u r, k}^{s u} \leq \operatorname{cap}_{s}^{s u} ; \forall s$

$U_{\text {tour }, k, b i}^{1}-U_{\text {tour }, k, b j}^{1}+\mid$ Node $1\left|. X_{\text {tour }, k, b i, b j}^{1} \leq\right|$ Node $1 \mid-1 ; \forall k$, tour $, b i, b j$

$\sum_{n 1 i} X_{\text {tour }, k, n 1 i, \text { node } 1}^{1}=\sum_{n 1 j} X_{\text {tour }, k, \text { node } 1, n 1 j}^{1} ; \forall k$, tour, node 1

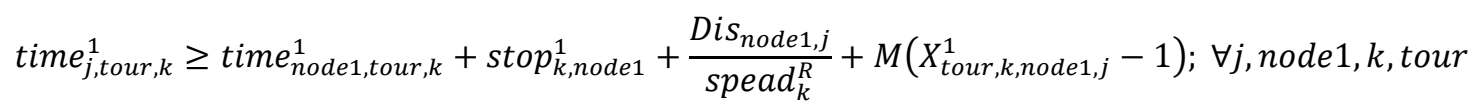

time $_{s, \text { tour }, k}^{1} \geq$ time $_{\text {node } 1, \text { tour }-1, k}^{1}+\operatorname{stop}_{k, \text { node } 1}^{1}+\frac{\text { Dis }_{\text {node } 1, s}}{\operatorname{spead}_{k}^{R}}+M\left(X_{\text {tour }-1, k, \text { node } 1, s}^{1}-1\right) ; \forall s$, node $1, k$, tour

8. $\sum_{\text {node } 1} X_{\text {tour }, k, \text { node } 1, j}^{1} \leq \bmod \left(\right.$ time $\left._{j, \text { tour }, k}^{1}, 24\right) \leq 16 . \sum_{\text {node } 1} X_{\text {tour }, k, n o d e 1, j}^{1} ; \forall j, k$, tour

time $e_{\text {node } 1, \text { tour }, k} \leq 48 ; \forall$ node $1, k$, tour

$\sum_{j} Y_{j} \leq N p$

$\sum_{\text {day }} \sum_{\text {tour }} \sum_{v} X_{\text {day }, c, \text { tour }, v} \geq s n_{c} ; \forall c$

$\sum_{\text {tour }} \sum_{v} X_{\text {day }, c, \text { tour }, v} \leq 1 ; \forall c$, day

$\sum_{j} \sum_{\text {tour }} \sum_{v} Q_{j, c . t o u r, v}^{b}=\operatorname{dem}_{c} ; \forall c$

$\sum_{c} \sum_{\text {tour }} \sum_{v} Q_{\text {day }, j, c, t o u r, v} \leq u_{\text {day }, j}^{B} ; \forall$ day, $j$

$\sum_{j} \sum_{\text {tour }} \sum_{v} Q_{\text {day,j,c,tour }, v} \leq u_{\text {day, }, c}^{c} ; \forall$ day, $c$

$\sum_{c} \sum_{\text {tour }} \sum_{v} Q_{j, c . t o u r, v}^{b}=\sum_{s} \sum_{\text {tour }} \sum_{k} Q_{s, j, t o u r, k}^{s u} ; \forall j$

$\sum_{j} z_{v, j}^{V}=1 ; \forall v$

$\sum_{c} \sum_{\text {tour }} Q_{j, c . t o u r, v}^{b} \leq M . z_{v, j}^{V} ; \forall j, v$

$z_{v, j}^{V} \leq e_{j v} ; \forall v, j$

$\sum_{c} X_{\text {tour }, v, j, c}^{2} \leq z_{v, j}^{V} ; \forall j, v$, tour 


$$
\begin{aligned}
& \sum_{c} Q_{j, c, t o u r, v}^{b} \leq \operatorname{cap}_{v}^{V} ; \forall j, v, \text { tour } \\
& \sum_{n 2 i} \sum_{n 2 j} \sum_{\text {tour }} \frac{D i s_{n 2 i, n 2 j}^{M}}{\operatorname{spead}_{v}^{V}} \cdot X_{\text {tour }, v, n 2 i, n 2 j}^{2} \leq f_{v} ; \forall v \\
& Q_{j, c, t o u r, v}^{b} \leq M . \sum_{n 2 i} X_{\text {tour }, v, n 2 i, c}^{2} ; \forall j, c, v, \text { tour } \\
& U_{\text {tour }, v, c i}^{2}-U_{\text {tour }, v, c j}^{2}+\mid \text { Node2 }\left|. X_{\text {tour }, v, c i, c j}^{2} \leq\right| \text { Node2 } \mid-1 ; \forall v, \text { tour }, c i, c j \\
& \sum_{n 2 i} X_{\text {tour }, v, n 2 i, n o d e 2}^{2}=\sum_{n 2 j} X_{\text {tour }, v, \text { node } 2, n 2 j}^{2} ; \forall v, \text { tour }, \text { node2 } \\
& \operatorname{time}_{c, \text { tour }, v}^{2} \geq \operatorname{time}_{\text {node2,tour }, v}^{2}+\operatorname{stop}_{v, \text { node } 2}^{2}+\frac{\operatorname{Dis}_{\text {node }, c}^{M}}{\operatorname{spead}_{v}^{V}}+M\left(X_{\text {tour }, v, \text { node }, c}^{2}-1\right) ; \forall c, \text { node } 2, v, \text { tour } \\
& \text { time }_{j, \text { tour }, v}^{2} \geq \text { time }_{\text {node2,tour }-1, v}^{2}+\operatorname{stop}_{v, \text { node } 2}^{2}+\frac{\text { Dis }_{\text {node } 2, j}^{M}}{\operatorname{spead}_{v}^{V}}+M\left(X_{\text {tour }-1, v, \text { node }, j}^{2}-1\right) ; \forall j, \text { node } 2, v, \text { tour } \\
& \text { 8. } \sum_{\text {node } 2} X_{\text {tour }, v, j, n o d e 2}^{2} \leq \bmod \left(\text { time }_{j, t o u r, v}^{2}, 24\right) \leq 16 . \sum_{\text {node } 2} X_{\text {tour }, v, j, \text { node } 2}^{2} ; \forall j, v, \text { tour } \\
& w L_{c} \cdot \sum_{n o d e 2} X_{\text {tour }, v, \text { node }, c}^{2} \leq \bmod \left(\text { time }_{c, \text { tour }, v}^{2}, 24\right) \leq w R_{c} \cdot \sum_{\text {node } 2} X_{\text {tour }, v, \text { node }, c}^{2} ; \forall c, v, \text { tour } \\
& \text { time } \text { node2,tour }, v^{2} \leq 168 ; \forall \text { node2, }, \text {, tour } \\
& X_{\text {day,node,tour }, v}=\left\{\begin{array}{c}
1 \text { if day }-1<\frac{\text { time }_{\text {node2,tour }, v}^{2}}{24} \leq \text { day } ; \forall \text { day, node } 2, \text { tour }, v \\
0 \quad \text { else }
\end{array}\right. \\
& Q_{\text {day }, j, c, \text { tour }, v}=Q_{j, c . t o u r, v}^{b} . X_{\text {day,c,tour }, v} ; \forall \text { day, }, c, \text { tour }, v \\
& \sum_{\text {tour }} \sum_{v} \sum_{g=1}^{k} X_{\text {mod }(\text { day }+(g-1), 7), c, t o u r, v} \leq k-1+M . \theta_{c} ; \forall \text { day, } c \in C_{k} \\
& \theta_{c} \leq \sum_{\text {day }} \sum_{\text {tour }} \sum_{v} X_{\text {day }, c, \text { tour }, v}-s n_{c} ; \forall c \\
& \theta_{c} \geq \frac{\sum_{\text {day }} \sum_{\text {tour }} \sum_{v} X_{\text {day }, c, t o u r, v}-s n_{c}}{M} ; \forall c \\
& z_{k, S}^{R} \in\{0,1\} ; k \in K, s \in S \\
& Y_{j} \in\{0,1\} ; j \in B \\
& X_{\text {tour }, k, n 1 i, n 1 j}^{1} \in\{0,1\} ; \text { tour } \in \text { tourR, } k \in K, n 1 i \in \text { Node } 1, n 1 j \in \text { Node } 1 \\
& Q_{s, j, t o u r, k}^{\text {su }} \geq 0 ; s \in S, j \in B, \text { tour } \in \text { tourR, } k \in K
\end{aligned}
$$




$$
\begin{aligned}
& \text { time }_{\text {node } 1, \text { tour }, k}^{1} \geq 0 ; \text { node } 1 \in \text { Node } 1, \text { tour } \in \text { tour } R, k \in K \\
& U_{\text {tour }, k, j}^{1} \geq 0 ; \text { tour } \in \text { tour } R, k \in K, j \in B \\
& z_{v, j}^{V} \in\{0,1\} ; v \in V, j \in B \\
& X_{\text {tour }, v, n 2 i, n 2 j}^{2} \in\{0,1\} ; \text { tour } \in \text { tourV }, v \in V, n 2 i \in \text { Node } 2, n 2 j \in \text { Node2 } \\
& Q_{j, c . t o u r, v}^{b} \geq 0 ; j \in B, c \in C, \text { tour } \in \operatorname{tour} V, v \in V \\
& \text { time }_{\text {node } 2, \text { tour }, v}^{2} \geq 0 ; \text { node } 2 \in \text { Node, tour } \in \operatorname{tour} V, v \in V \\
& X_{\text {day,node2,tour, }} \in\{0,1\} ; \text { day } \in \text { Day, node2 } \in \text { Node, tour } \in \text { tourV }, v \in V \\
& Q_{\text {day,j,c,tour, }} \geq 0 ; \text { day } \in \text { Day, } j \in B, c \in C, \text { tour } \in \text { tourV }, v \in V \\
& U_{\text {tour }, v, c}^{2} \geq 0 ; \text { tour } \in \text { tourV }, v \in V, c \in C \\
& \theta_{c} \in\{0,1\} ; c \in C
\end{aligned}
$$

Equation (1) is the objective function which is divided into two sections. The total cost in the first echelon is shown by $Z_{1}$, which minimizes the chartering cost of the road vehicles, the locating cost of the onshore bases to install central warehouses, the variable cost of the cargoes in central warehouses, the purchasing cost of the cargoes from suppliers and the transportation cost of the cargoes from suppliers to onshore bases. The total cost in the second echelon is shown by $Z_{2}$. It minimizes the cost of chartering the marine vehicles plus the transportation cost of the cargoes from onshore bases to offshore units.

Constraint (2) assures that if road vehicle $k$ is rented, this vehicle must be assigned to a certain supplier. The capacity of road vehicle $k$ is controlled by Constraint (3). Constraint (4) means road vehicle $k$ cannot start a tour from supplier $s$ unless this vehicle has assigned to this supplier previously. Constraint (5) means no cargo can be sent to onshore bases by road vehicle $k$, before assigning it to a certain supplier. Constraint (6) implies that sending cargoes from supplier $s$ to onshore base $j$ by road vehicle $k$ is permitted if only road vehicle $k$ visits onshore base $j$. Constraint (7) means it is not allowed to send cargoes to potential onshore base $j$ unless this potential onshore base has been selected as a central warehouse previously. In addition, the capacity of central warehouse is checked. The capacity of supplier $s$ is controlled by Constraint (8). Constraint (9) is used to omit sub-tours in the first echelon. 
Continuity of tours in the first echelon is ensured by Constraint (10). The visiting time of road vehicles in each onshore base is calculated by Constraint (11). Constraint (12) calculates the loading time of road vehicles from suppliers. Visiting onshore bases between 8:00 and 16:00 is controlled by Constraint (13). Constraint (14) means the maximum hours to send cargoes from suppliers to onshore bases must be less than 48 hours. Constraint (15) means that the number of optimal onshore bases cannot be more than $\mathrm{Np}$.

The number of needed weekly visits for each offshore unit is checked by Constraint (16). Constraint (17) ensures that each offshore unit must not be visited more than once in a day. Sending the needed demands of offshore units is ensured by Constraint (18). Constraint (19) means that the volume of cargoes, which are sent to offshore units on a certain day, must not be exceeded from onshore base's capacity. The capacity of offshore units to receive cargoes on a certain day is checked by Constraint (20). Constraint (21) shows that all cargoes that enter to an onshore base from different suppliers must be equal to all cargoes which are sent to different offshore units during the horizon time. Constraint (22) states that marine vehicles cannot be assigned to more than one onshore base. Constraint (23) means that no cargo can be sent to offshore units by marine vehicle $v$, if only this vehicle has been assigned to a certain onshore base previously.

Constraint (24) states the allowable type of marine vehicles, which can be berthed in central warehouses. Constraint (25) means that a marine vehicle cannot be sent from a warehouse to offshore units unless it has been assigned to that warehouse before. The capacity of marine vehicle $v$ is controlled by Constraint (26). Constraint (27) checks the number of hours, in which marine vehicles can be used during a week. Constraint (28) means that sending cargoes from warehouse $j$ to offshore unit $c$ by vehicle $v$ is permitted if only the same vehicle visits the same offshore unit. Constraint (29) is used to omit sub-tours in the second echelon. Continuity of tours in the second echelon is ensured by Constraint (30). The visiting time of offshore unit $c$ by marine vehicle $v$ is calculated by Constraint (31). The loading time of marine vehicle $v$ from warehouse $j$ is calculated by Constraint (32). Loading from warehouse $j$ by marine vehicles between 8:00 and 16:00 is controlled by Constraint (33). Unloading in offshore unit $c$ by marine vehicles between 7:00 and 19:00 is checked by Constraint (34). Constraint (35) means that the maximum hours to send cargoes from warehouses to offshore units must be less than 168 hours. Constraint (36) shows that if offshore unit $c$ is visited by vehicle $v$ on a certain day or not. The volume of cargoes, which is received by offshore unit $c$ in a special day, is obtained by Constraint (37). Constraints (38) to (40) are related to the spread of departures. It is ensured that $k$ needed visits of offshore unit $c$ 
during a week; do not occur in the following $k$ days. Constraints (41) to (54) define the domains of the variables.

\subsection{Linearization of the model}

A linear programming model consists of a linear objective function and linear constraint(s). Linear programming is useful for solving several practical problems such as LRPs. The main advantage of linear models rather than nonlinear models is the simplicity of them. Nonlinear models are complex, and most of them need a polynomial time to find the solution (Chen et al., 2011).

By using binary variables and preprocessing non-linear constraints, we linearize our proposed model to obtain the solution in a reasonable time. Constraint (13) must be changed to Constraints (55) and (56), Constraint (33) to Constraints (57) and (58), Constraint (34) to Constraints (59) and (60), Constraint (36) to Constraints (61)-(67), and finally Constraint (37) to Constraints (68)-(70).

$$
\begin{aligned}
& \text { 8. } \sum_{\text {node } 1} X_{\text {tour }, k, \text { node } 1, j}^{1} \leq \text { time }_{j, \text { tour }, k}^{1}-24 . \xi_{j, k, t o u r}^{1} \leq 16 . \sum_{\text {node } 1} X_{\text {tour }, k, \text { node } 1, j}^{1} ; \forall j, k, \text { tour } \\
& \frac{\text { time }_{j, \text { tour }, k}^{1}}{24}-1+\frac{1}{M} \leq \xi_{j, k, \text { tour }}^{1} \leq \frac{\text { time }_{j, \text { tour }, k}^{1}}{24} ; \forall j, k, \text { tour } \\
& \text { 8. } \sum_{\text {node } 2} X_{\text {tour }, v, j, \text { node } 2}^{2} \leq t i m e_{j, t o u r, v}^{2}-24 . \xi_{j, v, \text { tour }}^{2} \leq 16 . \sum_{\text {node } 2} X_{\text {tour }, v, j, n o d e 2}^{2} ; \forall j, v, \text { tour } \\
& \frac{\text { time }_{j, \text { tour }, v}^{2}}{24}-1+\frac{1}{M} \leq \xi_{j, v, \text { tour }}^{2} \leq \frac{\text { time }_{j, \text { tour }, v}^{2}}{24} ; \forall j, v, \text { tour } \\
& w L_{c} \cdot \sum_{\text {node } 2} X_{\text {tour }, v, \text { node } 2, c}^{2} \leq \text { time }_{c, \text { tour }, v}^{2}-24 . \xi_{c, v, \text { tour }}^{2} \leq w R_{c} \cdot \sum_{\text {node } 2} X_{\text {tour }, v, \text { node } 2, c}^{2} ; \forall c, v, \text { tour } \\
& \frac{\text { time }_{c, \text { tour }, v}^{2}}{24}-1+\frac{1}{M} \leq \xi_{c, v, \text { tour }}^{2} \leq \frac{\text { time }_{c, \text { tour }, v}^{2}}{24} ; \forall c, v, \text { tour }
\end{aligned}
$$

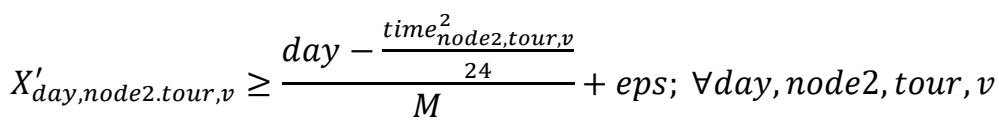

$$
\begin{aligned}
& X_{\text {day, node2,tour }, v}^{\prime} \leq 1+\frac{\text { day }-\frac{\text { time }_{\text {node } 2, \text { tour }, v}^{2}}{24}}{M} ; \forall \text { day, node } 2, \text { tour }, v \\
& X_{\text {day, node2,tour }, v}^{\prime \prime} \geq \frac{\frac{\text { time }_{\text {node2,tour }, v}^{2}}{24}-(\text { day }-1)}{M} ; \forall \text { day, node } 2, \text { tour }, v \\
& X_{\text {day, node2,tour }, v}^{\prime \prime} \leq 1+\frac{\frac{\text { time }_{\text {node2,tour }, v}^{2}}{24}-(\text { day }-1)}{M}-e p s ; \forall \text { day, node } 2, \text { tour }, v \\
& X_{\text {day,node2,tour }, v} \leq X_{\text {day,node2,tour }, v}^{\prime} ; \forall \text { day, node2, tour, } v
\end{aligned}
$$




$$
\begin{aligned}
& X_{\text {day,node2,tour }, v} \leq X_{\text {day,node2,tour, },}^{\prime \prime} ; \forall \text { day, node2, tour, } v \\
& X_{\text {day,node2,tour, },} \geq X_{\text {day,node2,tour, },}^{\prime}+X_{\text {day,node2,tour }, v}^{\prime \prime}-1 ; \forall \text { day, node2, tour }, v \\
& Q_{\text {day }, j, c, \text { tour }, v} \leq Q_{j, c . t o u r, v}^{b} ; \forall \text { day, } j, c, \text { tour }, v \\
& Q_{d a y, j, c, t o u r, v} \leq M . X_{\text {day,c,tour }, v} ; \forall \text { day, }, j, c, \text { tour }, v \\
& Q_{d a y, j, c, t o u r, v} \geq Q_{j, c . t o u r, v}^{b}+M .\left(X_{d a y, c, t o u r, v}-1\right) ; \forall \text { day, },, c, \text { tour }, v \\
& \text { ( } X_{\text {day,node2,tour }, v}^{\prime}, X_{\text {day, node2,tour }, v}^{\prime \prime} \in\{0,1\} ; \xi_{j, k, \text { tour }}^{1}, \xi_{j, k, \text { tour }}^{2}, \xi_{c, k, \text { tour }}^{2} \text { : integer) }
\end{aligned}
$$

\section{Solution approach}

The 2E-LRP integrates two different decision levels. Strategic level which is related to facility location problem, and tactical level which is about routing problem. Each of these problems is NP-hard, and the combination of them is a very complex optimization problem. Solving such a hard problem using MILP solvers (e.g., CPLEX) is time-consuming, and it is not possible in some cases.

The solution approach to solve the proposed model has two phases. In the first phase, a Lagrangean decomposition method is used. Then, a VRPTW by considering Equations (16), (20) and (38-40) is solved. These equations are not considered in Lagrangean decomposition due to their complexity. Figure 4 shows the details. 


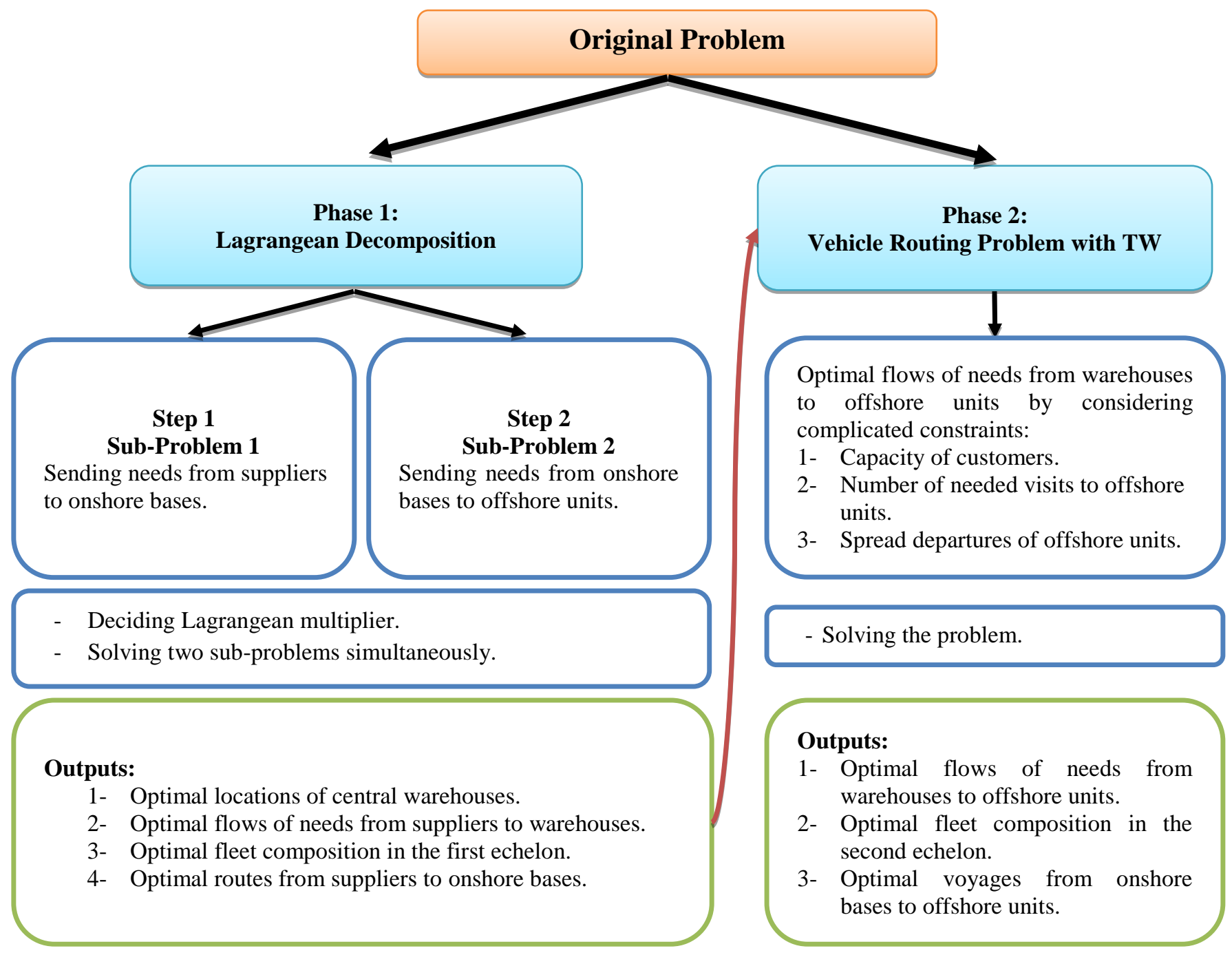

Figure 4. Solution approach

The Lagrangean decomposition that is developed in this study is a particular case of Lagrangean relaxation. In Lagrangean relaxation method, some constraints are added to the objective function with a penalty term proportional to the amount of violation of the dualized constraints (Geoffrion, 1974). On the other hand, in the Lagrangean decomposition, the main problem is divided into several sub-problems by defining a copy of the decision variables in each generated sub-problem. In addition, new constraints are added in order to ensure the similarity between the new and the original variables. Furthermore, some penalty terms are considered in the objective function (Guignard and Kim, 1987).

Lagrangean decomposition method is a popular technique to solve complicated problems such as multi-periodic train timetabling problem (Zhou et al., 2017), and multi-period supply investment planning problem (Oliveira et al., 2013). 
Defining a strategy to divide our problem is an important step. Our decomposition is based on Equation (21). As a result, we obtain the following sub-problems:

1) Sending needs from suppliers to onshore bases.

2) Sending needs from onshore bases to offshore units.

At the end of the first phase and after solving these sub-problems, the optimal locations of central warehouses are determined. Then, the VRPTW problem is solved in the second phase.

\subsection{Phase 1: Lagrangean decomposition}

In this paper, a Lagrangean decomposition method is developed by dividing the original problem into two sub-problems. Figure 5 illustrates an overview of the Lagrangean decomposition algorithm.

The following model is considered for the Lagrangean decomposition method.

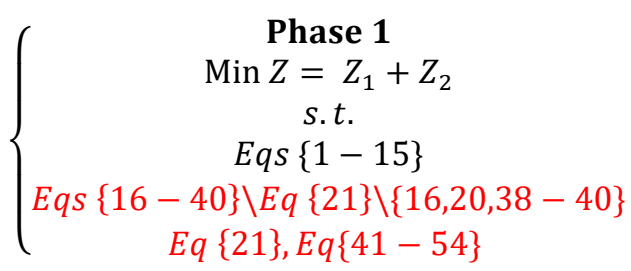

By not considering Equation, the original problem is divided into the following two subproblems:

- Sub-problem 1: Equations (1-15) are related to this step. It shows the flow of needs from suppliers to onshore bases. In this step, the total cost of sending needs from suppliers to central warehouses should be minimized.

- Sub-problem 2: Equations (16-40) except spread departure equations (16, 20, 38-40) are related to this step. It shows the flow of needs from onshore bases to offshore units. In this step, the total cost of sending needs from warehouses to offshore units should be kept at a minimum. 


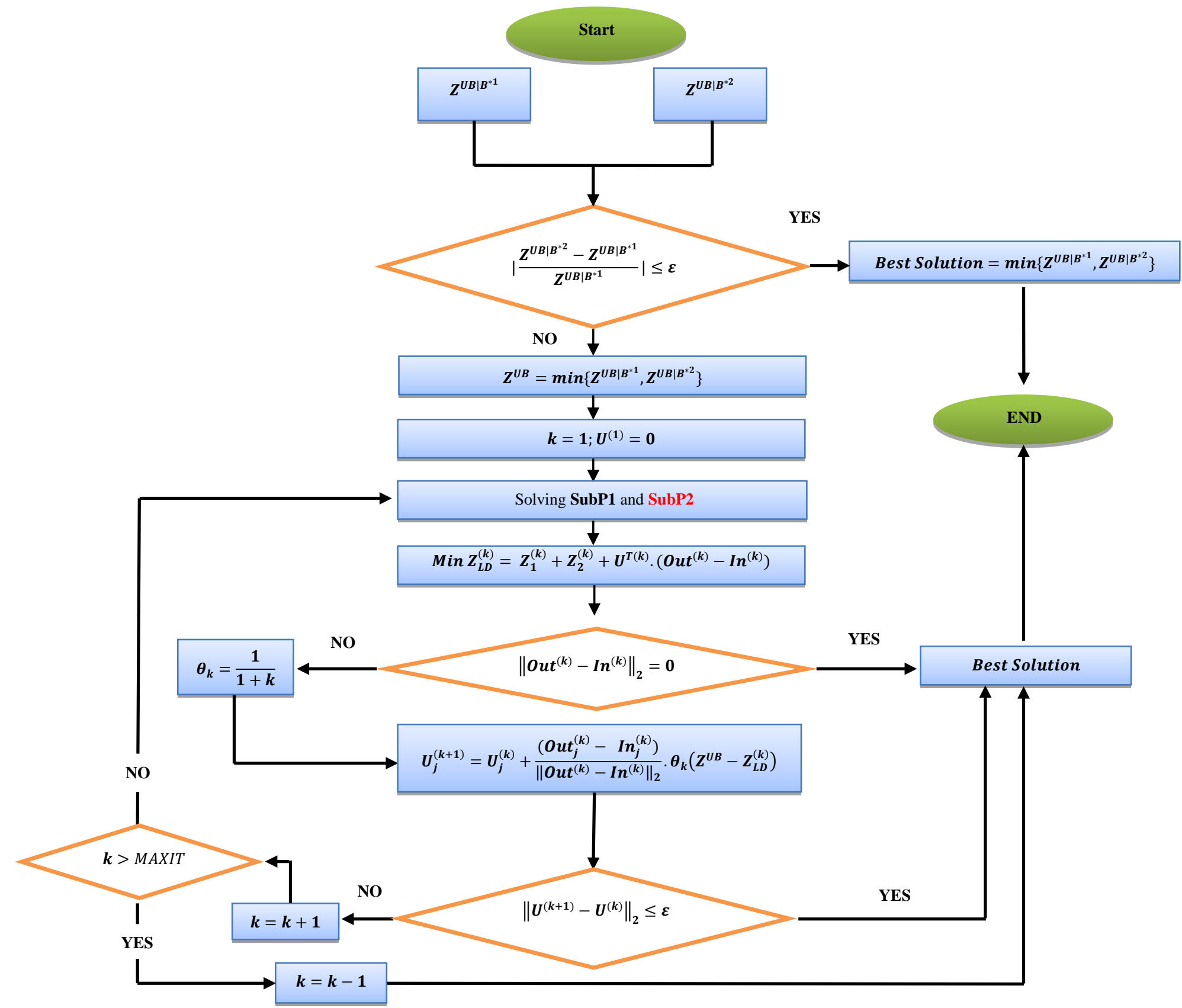

Figure 5. Lagrangean decomposition algorithm

The main problem should be separated. To this aim, Equations (72) and (73) are defined in the first and second steps of the Lagrangean decomposition method, respectively. Equation (72) is related to the input flow to each onshore base. Besides, Equation (73) states the output flow from each onshore base.

$$
\begin{aligned}
& \operatorname{In}_{j}=\sum_{s} \sum_{\text {tour }} \sum_{k} Q_{s, j, \text { tour }, k}^{\text {su }} ; \forall j \in B \\
& \text { out }_{j}=\sum_{c} \sum_{\text {tour }} \sum_{v} Q_{j, c . t o u r, v}^{b} ; \forall j \in B
\end{aligned}
$$


Equation (21) is complex and should be redefined to decompose the problem. Thus, it is replaced by Equation (74). The objective function is defined in Equation (75), where $U$ is a Lagrangean multiplier convex, and $(O u t-I n)$ is the difference between the outputs and the inputs of warehouses.

$O u t_{j}=I n_{j} \forall j \in B$

$\operatorname{Min} Z_{L D}=Z_{1}+Z_{2}+U^{T} .($ Out - In $)$

In the next stage, two sub-problems are defined by Equations (76) and (77). After decomposing the original problem to the sub-problems, the initial value, updated multiplier $U$, and stop conditions of the algorithm must be determined (Guignard and Kim, 1987).

$$
\begin{gathered}
\text { SubP1: } \\
\left\{\begin{array}{c}
\text { Min } Z_{1}-U^{T} . \text { In } \\
\text { s.t. } \\
E q s\{1-15\} \\
I n_{j}=\sum_{s} \sum_{\text {tour }} \sum_{k} Q_{s, j, t o u r, k}^{s u} ; \forall j \in B \\
\sum_{j} I_{i}=\sum_{c} \text { dem }_{c} ; \forall j \in B \\
\text { SubP2: } \\
\text { Min } Z_{2}+U^{T} . \text { Out } \\
\text { s.t. } \\
\text { Eqs }\{16-40\} \backslash\{21\} \backslash\{16,20,38-40\} \\
\text { Out } t_{j}=\sum_{c} \sum_{\text {tour }} \sum_{v} Q_{j, c . t o u r, v}^{b} ; \forall j \in B
\end{array}\right.
\end{gathered}
$$

\subsubsection{Initial value of multiplier $U$}

By setting $U^{(1)}=0$, there is no connection between the two sub-problems, and they should be optimized separately. Besides, the value of $Z^{*}$ that is obtained by setting $U=0\left(Z^{*}=\right.$ $Z_{1}^{*}+Z_{2}^{*}$ ) is a lower bound of the original problem. This value is shown by $Z^{L}$.

\subsubsection{Updating multiplier $U$}

In order to update multiplier $U$, the following formulation is suggested, where $k$ shows the number of iterations. In this formula, $O u t_{j}^{(k)}, I n_{j}^{(k)} ; \forall j \in B$ indicate the input and output of warehouses in iteration $k$. Furthermore, $\theta_{k}=\frac{1}{1+k}$, and $Z^{U B}$ is an upper bound of the original problem. 


$$
U_{j}^{(k+1)}=U_{j}^{(k)}+\frac{\left(O u t_{j}^{(k)}-I n_{j}^{(k)}\right)}{\left\|O u t^{(k)}-I n^{(k)}\right\|_{2}} \cdot \theta_{\boldsymbol{k}}\left(Z^{U B}-Z_{L D}^{(k)}\right)
$$

In addition, the following relations exist.

- If Out ${ }_{j}^{(k)}-$ In $_{j}^{(k)}>0$ then $U_{j}^{(k+1)}>U_{j}^{(k)}$

- If Out ${ }_{j}^{(k)}-$ In $_{j}^{(k)}<0$ then $U_{j}^{(k+1)}<U_{j}^{(k)}$

\subsubsection{Upper bounding procedure}

In this section, a particular heuristic method for finding a valid upper bound is developed. First, SubP1 by considering $U=0$ is solved, and the optimal locations of central warehouses $\left(B^{* 1} \subseteq B\right)$, and the optimal input for each warehouse $\left(I n_{j} ; \forall j \in B^{* 1}\right)$ are obtained. In this case, the optimal value of the objective function is shown by $Z_{1}^{*}$. In the next step, SubP2 by considering $U=0$, and setting the output of each warehouse by the input of each warehouse which was issued in SubPl $\left(O u t_{j}=I n_{j} ; \forall j \in B^{* 1} \& O u t_{j}=0 ; \forall j \notin B^{* 1}\right)$, is solved. In this case, the optimal value of the objective function is shown by $Z^{* 2 \mid B^{* 1}}$. Finally, a sub-optimal solution, which is an upper bound for the original problem is obtained $\left(Z^{U B \mid B^{* 1}}=Z_{1}^{*}+\right.$ $\left.Z^{* 2 \mid B^{* 1}}\right)$.

Similarly, SubP2 by considering $U=0$ is solved, and the optimal locations of central warehouses $\left(B^{* 2} \subseteq B\right)$, and the optimal output for each warehouse $\left(O u t_{j} ; \forall j \in B^{* 1}\right)$ are decided. In this case, the optimal value of the objective function is shown by $Z_{2}^{*}$. In the next step, SubPl by considering $U=0$, and setting the input of each warehouse by the output of each warehouse which was issued in $\operatorname{SubP2}\left(\operatorname{In}_{j}=O u t_{j} ; \forall j \in B^{* 2} \& I n_{j}=0 ; \forall j \notin B^{* 2}\right)$, is

run. In this case, the optimal value of the objective function which is shown by $Z^{* 1 \mid B^{* 2}}$, is another suboptimal solution, and an upper bound for the original problem $\left(Z^{U B \mid B^{* 2}}=Z_{2}^{*}+\right.$ $Z^{* 1 \mid B^{* 2}}$ ). Generally, if $Z^{U B \mid B^{* 1}}=Z^{U B \mid B^{* 2}}$ or $\left|\frac{Z^{U B \mid B^{* 2}}-Z^{U B \mid B^{* 1}}}{Z^{U B \mid B^{* 1}}}\right| \leq \varepsilon$ (where $\varepsilon$ is the tolerance value), then the optimal solution of Phase 1 (Lagrangean decomposition method) has obtained. Then, $B^{* 1}$ or $B^{* 2}$ is considered as the optimal locations of central warehouses. Otherwise, $Z^{U B}=\min \left\{Z^{U B \mid B^{* 1}}, Z^{U B \mid B^{* 2}}\right\}$, which is considered as an upper bound of the problem. Then, the Lagrangean decomposition process starts.

\subsubsection{Stopping conditions}

Whenever one of the following conditions occurs, the Lagrangean decomposition process stops. Then, the second phase of the solution approach starts. 
$\|$ Out ${ }^{(k)}-\operatorname{In}^{(k)} \|_{2}=0$

$\left\|U^{(k+1)}-U^{(k)}\right\|_{2} \leq \varepsilon$

$k>$ MaxIt, MaxIt:Maximum number of admittable iteration

\subsection{Phase 2: Vehicle routing problem with time windows}

At the end of Phase 1 , the optimal locations $\left(B^{*} \subseteq B\right)$ of central warehouses, and the optimal input $\left(\operatorname{In}_{j}^{*} ; \forall j \in B^{*}\right)$ of each central warehouse are determined. In the second phase of the solution approach, and by considering the outputs of Phase 1, the optimal distribution of cargoes to offshore units is determined.

In this phase, a vehicle routing problem with time windows (VRPTW) should be solved while the number of needed visits for offshore units, capacities of offshore units to receive cargoes, and the spread of departure constraints are added to the problem. According to the outputs of Phase 1, the optimization model for the second phase is as follows:

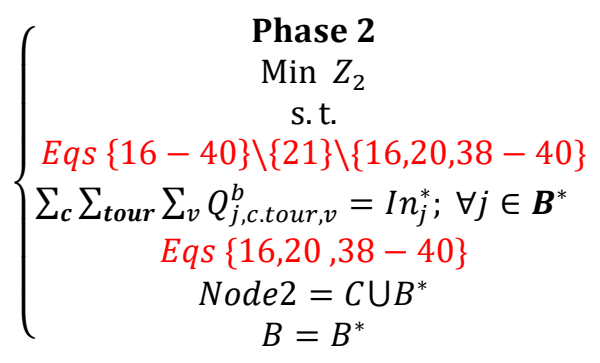

where Equation $\sum_{c} \sum_{\text {tour }} \sum_{v} Q_{j, c . t o u r, v}^{b}=I n_{j}^{*} ; \forall j \in B^{*}$ causes the input of each warehouse becomes equal to the optimal inputs. Furthermore, the number of needed visits by offshore units, the capacities of receiving cargoes and spread of departures are considered by using Equations (16, 20, 38-40).

\section{Computational results}

The new 2E-FCMPLRPTW model is applied in a real case in Iranian Offshore Oil Company (IOOC). IOOC is a subsidiary of National Iranian Oil Company (NIOC). GAMS (22.1) that is an optimization software has been utilized. The purpose of this section is to test and analyze how the model can be used for real cases in an offshore oil and gas industry.

\subsection{Case description}

NIOC with massive amounts of oil and gas resources is a very large oil company consisting of seventeen production companies. It's contribution in Iranian's crude oil exports 
is more than 33\%. The main operating area of IOOC (a subsidiary of NIOC) is in Persian Gulf and the sea of Oman.

IOOC includes four offshore units (i.e., Kharg, Lavan, Siri, and Gheshm), which produce oil and gas. Furthermore, there are three potential onshore bases along the coastline (i.e., Nakhilo, Bushehr, and Bahregan) with private ducks in order to berth marine vehicles and send the needed cargoes to offshore units. In addition, Shiraz and Esfahan are two main suppliers of IOOC. They supply needed cargoes for offshore units. The locations are shown in Figure 6.

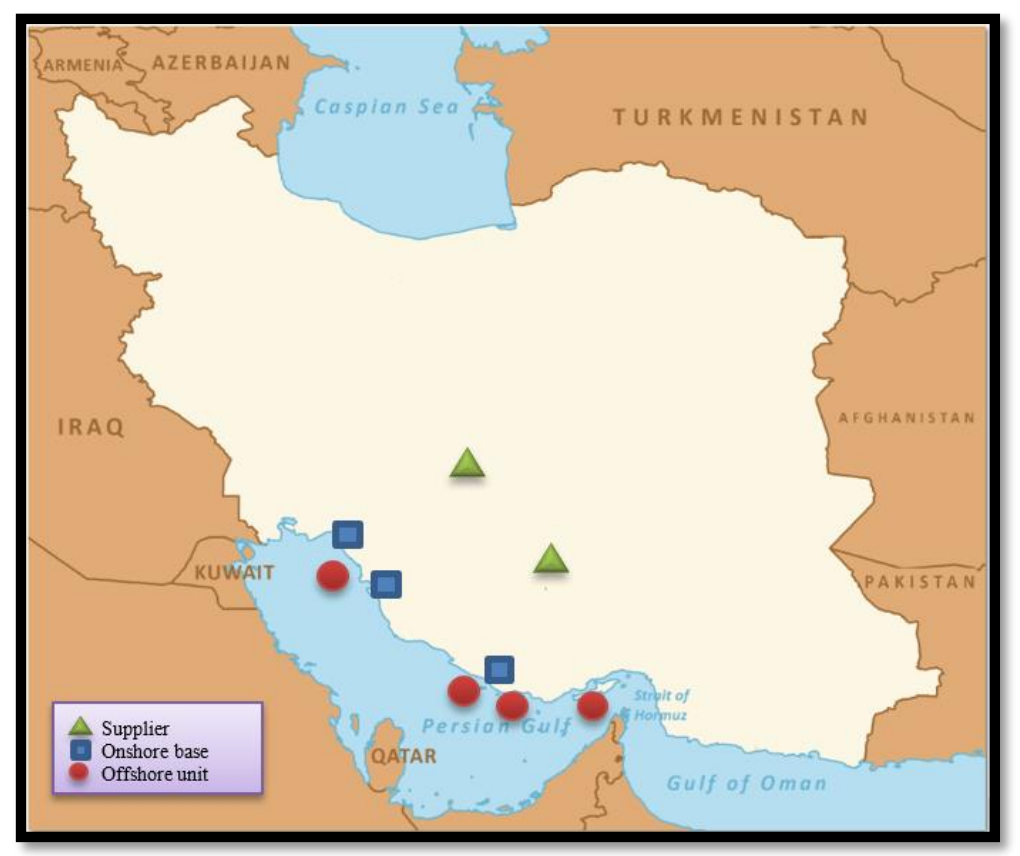

Figure 6. Locations of onshore bases, offshore units, and suppliers of IOOC

The lack of central warehouse(s) in IOOC is the most important reason for this study. The data of the local warehouse's inventories in IOOC are not integrated. Therefore, purchasing equipment or other consumable goods for an offshore unit without considering other inventories is a challenge in this company. In this company, road and marine vehicles are scheduled based on personal decisions for a long term. It is noticeable that installing warehouse(s) without considering other expenses (e.g., fleet sizing, transportation, and sailing costs) cannot be very helpful for the company. Therefore, it is aimed to install central warehouse(s) in potential onshore bases while the total cost is kept minimum.

In the first echelon, the capacities of suppliers to send cargoes are between $280 \mathrm{~m}^{3}$ and $300 \mathrm{~m}^{3}$. Furthermore, the capacities of onshore bases to receive needs are between $150 \mathrm{~m}^{3}$ and $200 \mathrm{~m}^{3}$. The duration of service time for loading in suppliers, and unloading in potential 
onshore bases is considered about two hours. Potential onshore bases have different variable costs, between $\$ 1.25$ and $\$ 1.375$ for one $\mathrm{m}^{3}$ of cargoes. In addition, installing central warehouse(s) has different fixed costs, between $\$ 37,500$ and $\$ 50,000$. Onshore bases have opening hours between 8:00 and 16:00, and unloading (road vehicles) is permitted during this time. Time-chartered rates for road vehicles are varied from $\$ 125$ to $\$ 225$ for two days, and the transportation cost is considered about $\$ 5$ per kilometer. The speed of road vehicles is varied between $90 \mathrm{Km}$ and $100 \mathrm{Km}$ per hour. The capacities of road vehicles are varied between $50 \mathrm{~m}^{3}$ and $70 \mathrm{~m}^{3}$. The purchasing cost of per unit of cargo from suppliers is different between $\$ 85$ and $\$ 90$. All demands must be sent to the potential onshore bases for two days.

In the second echelon, the demand of offshore units (by considering 10\% increase during the next 5 years) is varied between $20 \mathrm{~m}^{3}$ and $90 \mathrm{~m}^{3}$. All demands of offshore units must be supplied during seven days. Offshore units have certain capacities to receive cargoes, between $10 \mathrm{~m}^{3}$ and $45 \mathrm{~m}^{3}$, which are dependent on the days of week. It is supposed that the backload of offshore units is less than the cargoes, which are sent to them in a certain day. The number of weekly visits for offshore units is between two and four. The service time for loading supply vessels in potential onshore bases is considered eight hours. In addition, the service time for unloading in offshore units is considered between two and four hours. Onshore bases have opening hours between 8:00 and 16:00 for loading supply vessels. Besides, offshore units have opening hours between 7:00 and 19:00 for unloading supply vessels. The allowable type of supply vessels in potential onshore bases is different. The capacity of supply vessels is varied between $120 \mathrm{~m}^{3}$ and $160 \mathrm{~m}^{3}$. The rate of time-chartering for supply vessels is varied from $\$ 31,500$ to $\$ 47,250$ for a week. The sailing cost is between $\$ 100$ and $\$ 200$ for one hour. The sailing speed for supply vessels is different from 8 knot to 12 knot, and supply vessels are ready to be used for 144 hours in a week.

The results are obtained by a $2.8 \mathrm{GHz}$, Intel(R)Core(TM)i7(4CPUs) computer with $8 \mathrm{~GB}$ memory.

\subsection{Case study results}

The 2E-FCMPLRPTW model has been applied for the IOOC case. This model has been solved in a reasonable time by GAMS using CPLEX solver. There are 7,391 decision variables. Besides, the total cost is $\$ 317,560.5$. Table 6 comprises the results divided into two sections, namely the first and the second echelons. The first row is related to the CPU time and the total cost. The second row shows the number of selected suppliers and the onshore bases. The number of vehicles is shown in the third row. 
Table 6. Results of the 2E-FCMPLRPTW model for the case study

\begin{tabular}{cc|cc}
\hline \multicolumn{2}{c|}{ First echelon } & \multicolumn{2}{c}{ Second echelon } \\
\hline CPU time (sec.): 899.783; Cost (\$): 317,560.5 & Selected onshore base & B1\& B2 \\
\hline Selected supplier & S2 & No. of supply vessels & V1,V2 \\
\hline No. of trucks & (T1) & V3 \\
\hline
\end{tabular}

The total cost consists of $\$ 237,560.5$ weekly cost and $\$ 80,000$ fixed cost to install the central warehouses in Nakhilo (B1) and Bushehr (B2). The number of road vehicles can be reduced from three to two. In addition, the number of supply vessels can be reduced from four to three (i.e., current situation). This reduction in a number of vehicles corresponds to a total saving of $\$ 39,550$ for nine days. The optimal network and the related results are demonstrated in Figure 7.

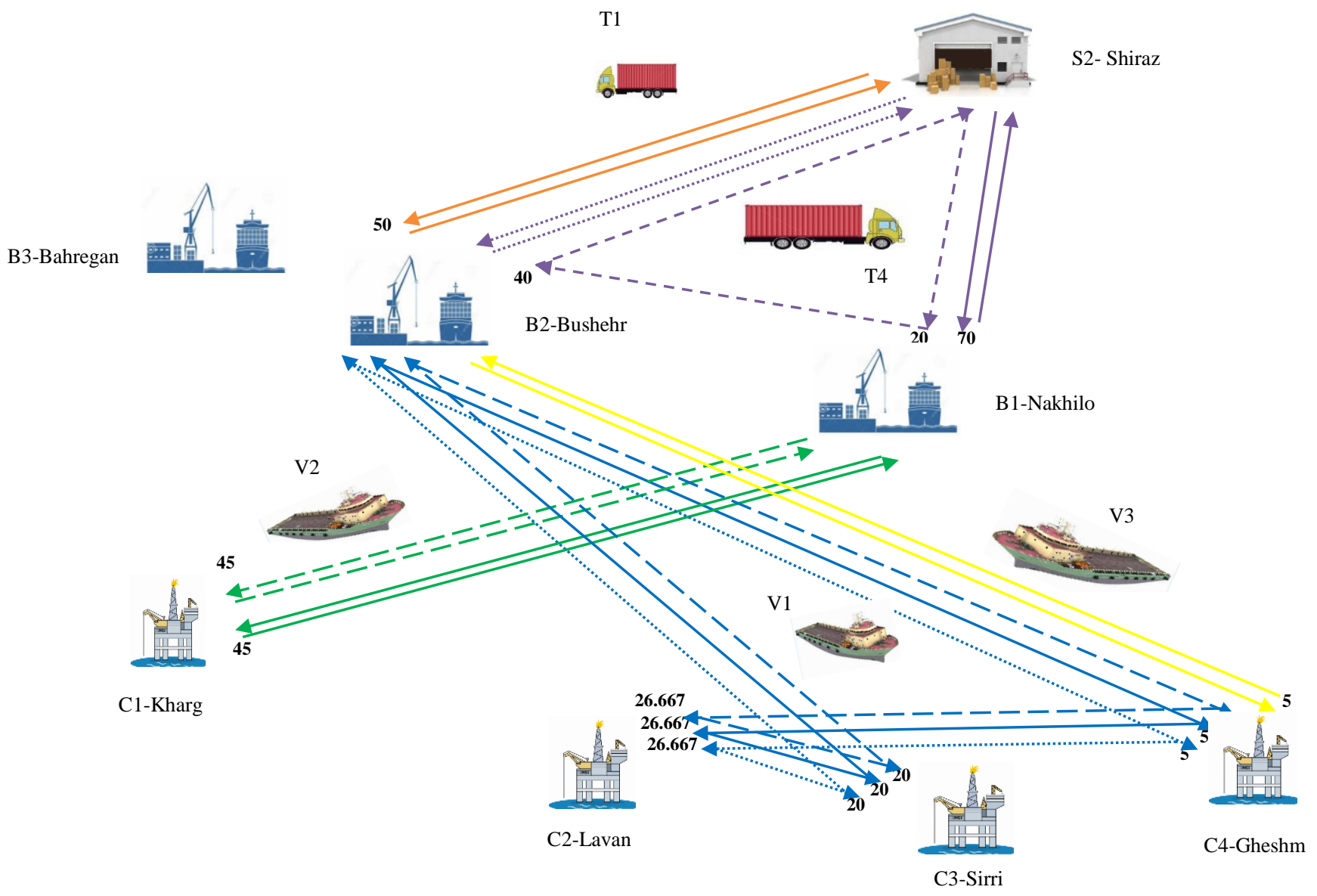

Figure 7. Results of the case study 


\subsection{Sensitivity analyses}

In most cases, a real schedule is different from the primary plan. Therefore, some changes are required. Sensitivity analyses are helpful for planners to make more reliable plans in uncontrollable events. In this section, we consider two scenarios to analyze the problem. They are illustrated in Figure 8. The goal of this section is to find whether it is possible to decrease the total cost by considering some changes in the original problem.

In the first scenario, the number of weekly visits to offshore units is studied. Offshore units $\mathrm{C} 2, \mathrm{C} 3$, and $\mathrm{C} 4$ need 10 visits during a week. We would like to know what will happen if the number of weekly visits of each offshore unit $(\mathrm{C} 2, \mathrm{C} 3, \mathrm{C} 4)$ is reduced by one visit.

Scenario 1: Reducing the number of weekly visits of operation regions.

Scenario 2: Opening some of offshore units during night.

Figure 8. Two scenarios of the sensitivity analyses

According to Table 7, the results show that there are three optimal alternatives for the IOOC by considering different total numbers of weekly visits. They are as follows:

- Alternative 1: By reducing just one weekly visit from offshore unit $\mathrm{C} 4$, the company will save $\$ 55,875$ in a week.

- Alternative 5: By reducing two weekly visits from offshore units $\mathrm{C} 2$ and $\mathrm{C} 4$, the company will save $\$ 66,875$ in a week.

- Alternative 7: By reducing just three weekly visits from offshore units C2, C3, and C4, the company will save $\$ 67,875$ in a week. 
Table 7. Results of decreasing weekly visits

\begin{tabular}{|c|c|c|c|c|c|c|c|c|}
\hline Alternative & $\begin{array}{l}\text { Offshore } \\
\text { units }\end{array}$ & $\begin{array}{c}\text { No. of } \\
\text { weekly } \\
\text { visits } \\
\text { (As is) }\end{array}$ & $\begin{array}{c}\text { No. of } \\
\text { weekly } \\
\text { visits } \\
\text { (To } \\
\text { be) } \\
\end{array}$ & $\begin{array}{c}\text { Cost } \\
(\$)\end{array}$ & $\begin{array}{c}\text { Supplier: } \\
\text { Trucks }\end{array}$ & $\begin{array}{c}\text { Onshore } \\
\text { Base: } \\
\text { Supply } \\
\text { vessels }\end{array}$ & $\begin{array}{c}\text { Saving } \\
\text { in a } \\
\text { week } \\
(\$)\end{array}$ & $\begin{array}{c}\text { Optimal } \\
\text { alternative }\end{array}$ \\
\hline 1 & $\mathrm{C} 2$ & 3 & 2 & $306,560.500$ & $\begin{array}{c}\text { S2: T1 \& } \\
\text { T4 }\end{array}$ & $\begin{array}{c}\text { B1: V2 } \\
\text { B2: V1, } \\
\text { V3 }\end{array}$ & 11,000 & - \\
\hline 2 & $\mathrm{C} 3$ & 3 & 2 & $317,060.500$ & $\begin{array}{c}\text { S2: T1 \& } \\
\text { T4 }\end{array}$ & $\begin{array}{c}\text { B1: V2 } \\
\text { B2: V1, } \\
\text { V3 }\end{array}$ & 500 & - \\
\hline 3 & $\mathrm{C} 4$ & 4 & 3 & $261,685.500$ & $\begin{array}{c}\text { S2: T1 \& } \\
\text { T4 }\end{array}$ & $\begin{array}{l}\text { B1: V2 } \\
\text { B2: V1 }\end{array}$ & 55,875 & $\mathrm{OK}$ \\
\hline 4 & $\mathrm{C} 2, \mathrm{C} 3$ & 6 & 4 & $305,560.500$ & $\begin{array}{c}\mathrm{S} 2: \mathrm{T} 1 \& \\
\mathrm{~T} 4\end{array}$ & $\begin{array}{c}\text { B1: V2 } \\
\text { B2: V1, } \\
\text { V3 }\end{array}$ & 12,000 & - \\
\hline 5 & $\mathrm{C} 2, \mathrm{C} 4$ & 7 & 5 & 250685.500 & $\begin{array}{c}\text { S2: T1 \& } \\
\text { T4 }\end{array}$ & $\begin{array}{l}\text { B1: V2 } \\
\text { B2: V1 }\end{array}$ & 66,875 & OK \\
\hline 6 & $\mathrm{C} 3, \mathrm{C} 4$ & 7 & 5 & 261185.500 & $\begin{array}{c}\text { S2: T1 \& } \\
\text { T4 }\end{array}$ & $\begin{array}{l}\text { B1: V2 } \\
\text { B2: V1 }\end{array}$ & 56,375 & - \\
\hline 7 & $\begin{array}{c}\mathrm{C} 2, \mathrm{C} 3, \\
\mathrm{C} 4\end{array}$ & 10 & 7 & 249685.500 & $\begin{array}{c}\text { S2: T1 \& } \\
\text { T5 }\end{array}$ & $\begin{array}{l}\text { B1: V2 } \\
\text { B2: V1 }\end{array}$ & 67,875 & OK \\
\hline
\end{tabular}

In the second scenario, the company wants to know what will happen if some onshore bases can be open during the night. The results of the seven alternatives are written in Table 8 . By considering opening hours during the night for onshore bases, no reduction can occur in the total cost of the optimal solution. In addition, it is required to hire 15 people $(\$ 2,850$ extra costs for a week) for each onshore base, which is open during the night.

Table 8. Results of not considering time windows for onshore bases

\begin{tabular}{|c|c|c|c|c|c|}
\hline Alternative & $\begin{array}{c}\text { Onshore } \\
\text { bases } \\
\text { with TW }\end{array}$ & $\begin{array}{l}\text { Selected supplier: } \\
\text { \#truck(s) / \#routes }\end{array}$ & $\begin{array}{c}\text { Selected } \\
\text { onshore } \\
\text { base }\end{array}$ & Cost (\$) & $\begin{array}{l}\text { Hiring cost of } \\
\text { persons for } \\
\text { a week (\$) }\end{array}$ \\
\hline 1 & B1, B2 & $\mathrm{S} 2: \mathrm{T} 1 \& \mathrm{~T} 4$ & $\begin{array}{c}\text { B1: V2 } \\
\text { B2: V1, V3 }\end{array}$ & $320,410.500$ & 2,850 \\
\hline 2 & B1, B3 & S2: $\mathrm{T} 1 \& \mathrm{~T} 3$ & $\begin{array}{c}\text { B1: V2 } \\
\text { B2: V1, V3 }\end{array}$ & $320,410.500$ & 2,850 \\
\hline 3 & B2, B3 & S2: T1 \& T4 & $\begin{array}{c}\text { B1: V2 } \\
\text { B2: V1, V3 }\end{array}$ & $320,410.500$ & 2,850 \\
\hline 4 & B1 & S2: T1 \& T3 & $\begin{array}{c}\text { B1: V2 } \\
\text { B2: V1, V3 }\end{array}$ & $323,260.500$ & 5,700 \\
\hline 5 & B2 & S2: T1 \& T3 & $\begin{array}{c}\text { B1: V2 } \\
\text { B2: V1, V3 }\end{array}$ & $323,260.500$ & 5,700 \\
\hline 6 & B3 & S2: T1 \& T3 & $\begin{array}{c}\text { B1: V2 } \\
\text { B2: V1, V3 }\end{array}$ & $323,260.500$ & 5,700 \\
\hline 7 & - & $\mathrm{S} 2: \mathrm{T} 1 \& \mathrm{~T} 4$ & $\begin{array}{c}\text { B1: V2 } \\
\text { B2: V1, V3 }\end{array}$ & $326,110.500$ & 8,550 \\
\hline
\end{tabular}




\section{Conclusion}

A novel two-echelon fleet composition mix periodic location-routing problem with time windows (2E-FCMPLRPTW) has been proposed in this paper. In addition, a novel Lagrangean decomposition method, which is a particular part of Lagrangean relaxation method has been developed. The proposed method consists of two phases. In the first phase, the main problem has been divided into two sub-problems using Lagrangean decomposition. Then, a VRPTW problem has been solved in the second phase. The computational study showed that the real-life instances can be solved by this approach using GAMS software, in a reasonable time. According to the results of this study, the company can save about $\$ 2,056,600$ each year due to the reduction of road vehicles from three to two, decrease in the number of supply vessels from four to three, and installing two new central warehouses. In the first scenario of the sensitivity analyses, the number of weekly visits of offshore units has been studied. The results showed that by reducing just one weekly visit from offshore unit $\mathrm{C} 4$, the company will save $\$ 55,875$ in a week. In addition, by reducing two weekly visits from offshore units $\mathrm{C} 2$ and $\mathrm{C} 4$, the company will save $\$ 66,875$ in a week. Finally, by reducing three weekly visits from offshore units $C 2, C 3$, and $C 4$, the company will save $\$ 67,875$ in a week. In the second scenario of the sensitivity analyses, considering opening hours during the night for onshore bases, no reduction in the number of vehicles, routes, and voyages occurred. Therefore, the total cost is fixed, and the company cannot have a profit. On the other hand, it is needed to hire fifteen persons by $\$ 2,850$ hiring cost in a week to handle the tasks, for each onshore base which is open during the night. Therefore, the best option for the company is keeping closed all onshore bases during the night.

There are some avenues for future research. It is valuable to consider and study some uncertain parameters, such as sailing time, offshore unit's demand, and service time in offshore units. The other important direction of future research is to consider environmental aspects for vehicles, their routes and voyages in both echelons. In addition, developing a path flow approach for the 2E-FCMPLRPTW model is another noticeable future study.

\section{Acknowledgement}

The authors would like to thank the editor and reviewers for the great comments that improved the quality of the paper significantly. This research has been supported by the NSERC Discovery grant. 


\section{References}

Aas, B., Gribkovskaia, I., Halskau Sr, O., \& Shlopak, A. (2007). Routing of supply vessels to petroleum installations. International Journal of Physical Distribution \& Logistics Management, 37(2), 164-179.

Aas, B., Halskau Sr, O., \& Wallace, S. W. (2009). The role of supply vessels in offshore logistics. Maritime Economics \& Logistics, 11(3), 302-325.

Albareda-Sambola, M., Díaz, J. A., \& Fernández, E. (2005). A compact model and tight bounds for a combined location-routing problem. Computers \& Operations Research, 32(3), 407-428.

Belenguer, J. M., Benavent, E., Prins, C., Prodhon, C., \& Calvo, R. W. (2011). A branch-andcut method for the capacitated location-routing problem. Computers \& Operations Research, 38(6), 931-941.

Chen, D. S., Batson, R. G., \& Dang, Y. (2011). Applied integer programming: Modeling and solution. John Wiley \& Sons.

Christiansen, M., Fagerholt, K., Rachaniotis, N. P., \& Stålhane, M. (2017). Operational planning of routes and schedules for a fleet of fuel supply vessels. Transportation Research Part E: Logistics and Transportation Review, 105, 163-175.

Contardo, C., Hemmelmayr, V., \& Crainic, T. G. (2012). Lower and upper bounds for the two-echelon capacitated location-routing problem. Computers \& Operations Research, 39(12), 3185-3199.

Cuesta, E. F., Andersson, H., Fagerholt, K., \& Laporte, G. (2017). Vessel routing with pickups and deliveries: an application to the supply of offshore oil platforms. Computers \& Operations Research, 79, 140-147.

Derbel, H., Jarboui, B., Hanafi, S., \& Chabchoub, H. (2012). Genetic algorithm with iterated local search for solving a location-routing problem. Expert Systems with Applications, 39(3), 2865-2871.

Drexl, M., \& Schneider, M. (2015). A survey of variants and extensions of the locationrouting problem. European Journal of Operational Research, 241(2), 283-308.

Dulebenets, M. A., \& Ozguven, E. E. (2017). Vessel scheduling in liner shipping: Modeling transport of perishable assets. International Journal of Production Economics, 184, 141156.

Ehmke, J. F., Campbell, A. M., \& Thomas, B. W. (2018). Optimizing for total costs in vehicle routing in urban areas. Transportation Research Part E: Logistics and Transportation Review, 116, 242-265. 
Fagerholt, K., \& Lindstad, H. (2000). Optimal policies for maintaining a supply service in the Norwegian Sea. Omega, 28(3), 269-275.

Geoffrion, A.M. (1974). Lagrangean relaxation and its uses in integer programming. Mathematical Programming, Study 2, 82-114.

Gribkovskaia, I., Laporte, G., \& Shlopak, A. (2008). A tabu search heuristic for a routing problem arising in servicing of offshore oil and gas platforms. Journal of the Operational Research Society, 59(11), 1449-1459.

Guignard, M., \& Kim, S. (1987). Lagrangean decomposition: A model yielding stronger Lagrangean bounds. Mathematical Programming, 39(2), 215-228.

Halvorsen-Weare, E. E., \& Fagerholt, K. (2011). Robust supply vessel planning. In Network optimization (pp. 559-573). Springer, Berlin, Heidelberg.

Halvorsen-Weare, E. E., Fagerholt, K., Nonås, L. M., \& Asbjørnslett, B. E. (2012). Optimal fleet composition and periodic routing of offshore supply vessels. European Journal of Operational Research, 223(2), 508-517.

Hemmelmayr, V. C., Cordeau, J. F., \& Crainic, T. G. (2012). An adaptive large neighborhood search heuristic for two-echelon vehicle routing problems arising in city logistics. Computers \& Operations Research, 39(12), 3215-3228.

Hof, J., Schneider, M., \& Goeke, D. (2017). Solving the battery swap station location-routing problem with capacitated electric vehicles using an AVNS algorithm for vehicle-routing problems with intermediate stops. Transportation Research Part B: Methodological, 97, 102-112.

Iachan, R. (2009). A Brazilian experience: 40 years using operations research at Petrobras. International Transactions in Operational Research, 16(5), 585-593.

Jacobsen, S. K., \& Madsen, O. B. (1980). A comparative study of heuristics for a two-level routing-location problem. European Journal of Operational Research, 5(6), 378-387.

Jarboui, B., Derbel, H., Hanafi, S., \& Mladenović, N. (2013). Variable neighborhood search for location routing. Computers \& Operations Research, 40(1), 47-57.

Jeong, Y., Saha, S., Chatterjee, D., \& Moon, I. (2018). Direct shipping service routes with an empty container management strategy. Transportation Research Part E: Logistics and Transportation Review, 118, 123-142.

Kisialiou, Y., Gribkovskaia, I., \& Laporte, G. (2018a). Robust supply vessel routing and scheduling. Transportation Research Part C: Emerging Technologies, 90, 366-378. 
Kisialiou, Y., Gribkovskaia, I., \& Laporte, G. (2018b). The periodic supply vessel planning problem with flexible departure times and coupled vessels. Computers \& Operations Research, 94, 52-64.

Koç, Ç., Bektaş, T., Jabali, O., \& Laporte, G. (2016). The fleet size and mix location-routing problem with time windows: Formulations and a heuristic algorithm. European Journal of Operational Research, 248(1), 33-51.

Lin, J. R., \& Lei, H. C. (2009). Distribution systems design with two-level routing considerations. Annals of Operations Research, 172(1), 329.

Nguyen, V. P., Prins, C., \& Prodhon, C. (2012). Solving the two-echelon location routing problem by a GRASP reinforced by a learning process and path relinking. European Journal of Operational Research, 216(1), 113-126.

Norlund, E. K., Gribkovskaia, I., \& Laporte, G. (2015). Supply vessel planning under cost, environment and robustness considerations. Omega, 57, 271-281.

Oliveira, F., Gupta, V., Hamacher, S., \& Grossmann, I. E. (2013). A Lagrangean decomposition approach for oil supply chain investment planning under uncertainty with risk considerations. Computers \& Chemical Engineering, 50, 184-195.

Pichka, K., Bajgiran, A. H., Petering, M. E., Jang, J., \& Yue, X. (2018). The two echelon open location routing problem: Mathematical model and hybrid heuristic. Computers \& Industrial Engineering, 121, 97-112.

Prins, C., Prodhon, C., \& Calvo, R. W. (2006). Solving the capacitated location-routing problem by a GRASP complemented by a learning process and a path relinking. 4OR, 4(3), 221-238.

Prodhon, C., \& Prins, C. (2014). A survey of recent research on location-routing problems. European Journal of Operational Research, 238(1), 1-17.

Rahmani, Y., Cherif-Khettaf, W. R., \& Oulamara, A. (2015). A local search approach for the two-echelon multi-products location-routing problem with pickup and delivery. IFACPapersOnLine, 48(3), 193-199.

Schwengerer, M., Pirkwieser, S., \& Raidl, G. R. (2012). A variable neighborhood search approach for the two-echelon location-routing problem. In: European Conference on Evolutionary Computation in Combinatorial Optimization. Springer, Berlin, Heidelberg pp. 13-24.

Shyshou, A., Gribkovskaia, I., \& Barceló, J. (2010). A simulation study of the fleet sizing problem arising in offshore anchor handling operations. European Journal of Operational Research, 203(1), 230-240. 
Shyshou, A., Gribkovskaia, I., Laporte, G., \& Fagerholt, K. (2012). A large neighbourhood search heuristic for a periodic supply vessel planning problem arising in offshore oil and gas operations. INFOR: Information Systems and Operational Research, 50(4), 195-204.

Vincent, F. Y., Lin, S. W., Lee, W., \& Ting, C. J. (2010). A simulated annealing heuristic for the capacitated location routing problem. Computers \& Industrial Engineering, 58(2), 288-299.

Zhao, Q., Wang, W., \& De Souza, R. (2018). A heterogeneous fleet two-echelon capacitated location-routing model for joint delivery arising in city logistics. International Journal of Production Research, 56(15), 5062-5080.

Zhou, W., Tian, J., Xue, L., Jiang, M., Deng, L., \& Qin, J. (2017). Multi-periodic train timetabling using a period-type-based Lagrangean relaxation decomposition. Transportation Research Part B: Methodological, 105, 144-173. 